\section{Cervical intradural disc protrusion}

Sir: I present the case of a 47 year old man who developed neck and right arm pain after a vigorous game of badminton. Two months later these symptoms increased in severity and he consulted his general practitioner who recorded a restriction of neck movements and some cervical tenderness but no abnormal neurological signs. The patient was treated with a soft collar and simple analgesics. Over the following week a reduction in pinprick and temperature sensation was observed in the left arm and leg and the patient was referred to the Regional Neurosurgical Centre at Newcastle General Hospital. On admission a reduction of power in the right arm and loss of the right triceps reflex were recorded.

A cervical myelogram showed a small round, intradural, extramedullary filling defect apparently lying posterior to the cord at the level of the C5/6 disc space. A CT myelogram showed an extradural disc protrusion at C5/6 indenting the dural sac and in continuity with an intradural mass which displaced the cord posterolaterally and to the left (fig). A diagnosis of an intradural cervical disc protrusion was therefore made.

An anterior cervical exploration and microdiscectomy was performed with a Cloward's fusion at $\mathrm{C5} / 6$. The posterior longitudinal ligament appeared intact and was incised and several extradural disc fragments were removed. A large intradural disc fragment was seen and was removed provoking a rush of CSF. A few smaller intradural disc fragments were then removed and the defect in the dura was closed with Surgicel. The patient made an uncomplicated recovery, the abnormal clinical signs resolved and the neck pain was much improved.

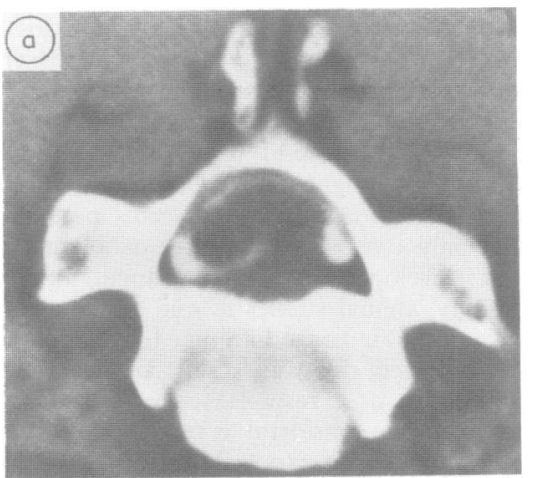

Fig (a) diagram of CT myelogram, (b) CT myelogram showing the disc protrusion at C5/6. The intradural portion is clearly demonstrated with compression and deformity of the cervical cord. been estimated by Lesoin to be $0.27 \%$. $^{2}$ a cervical disc is much less common and we could find only four such cases in the literature. ${ }^{13-5}$ typically sudden although as in our case it may be preceeded by a period of local and neck trauma in our patient is not unusual presented with paresis of an arm which in motor neuron and most (three of five) also one patient had a complete Brown-Séquard these patients presented with a Horner's syndrome (an unusual finding in extradural cervical disc prolapse). Although these clinical features can be produced by extradural combination of clinical symptoms and signs, disc fragment should be considered. formed in all of these five cases: two had a

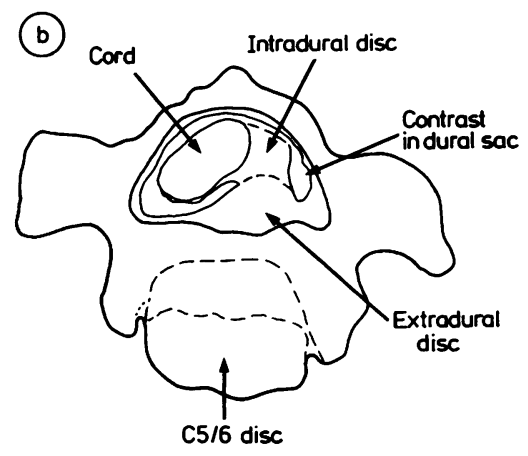

Intradural penetration of disc fragments from a prolapsed intervertebral disc is an unusual manifestation of disc disease and a review by Eisenberg identified 51 previously recorded cases. ${ }^{1}$ Ninety per cent of the reported cases have occurred in the lumbar spine. ${ }^{1}$ The incidence of the discovery of intradural disc fragments during surgery for prolapsed lumbar intervertebral discs has Intradural herniation of fragments from

The onset of symptoms in these patients is radicular pain. The absence of a history of and none of the previous cases suffered neck trauma immediately prior to the onset of symptoms although in two cases there was a history of a cervical injury at a road traffic accident several years earlier. All of the cases four of five patients was specified as lower had a spastic paraparesis. Four of these patients had a dissociated sensory loss and syndrome. At least one and probably two of disc protrusion, in the presence of this particularly where a Horner's syndrome is observed, the possibility of an intradural

Conventional myelography was percomplete myelographic block and in three an

References

1 Eisenberg RA, Bremer AM, Northup HM. Intradural herniated cervical disk: a case report and review of the literature. $A m J$ Neuroradiology 1986;7:492-4.

2 Lesoin $F$, Duquennoy $B$, Rousseaux $M, ~ ᄀ$ Servato R, Jomin M. Intradural rupture of lumbar intervertebral disc: report of three cases with review of the literature. Neurosurgery 1984;14:728-31.

3 Marega T. Ernia del disco cervicale epulsa nel sacco durale. Arch Putti Chir Organi Mor 1959;12:425-30.

4 Durig M, Zdrojewski B. Intradurale o sequestration einer cervikalen diskushernie. 3 Ein kausuisticher beitrag. Arch Orthop o Trauma Surg 1977;87:151-7.

5 Roda JM, Gonzalez C, Blaquez MG, Alvarez $D$ MP, Arguello C. Intradural herniated 음 cervical disc. Case report. J Neurosurg 1982; 57:278-80.

Accepted 10 April 1988 